\title{
Comparison of treatment results between holmium laser endourethrotomy and optical internal urethrotomy for urethral stricture
}

\author{
Slawomir A. Dutkiewicz • Mariusz Wroblewski
}

Received: 28 August 2011/ Accepted: 14 November 2011/Published online: 30 November 2011

(C) The Author(s) 2011. This article is published with open access at Springerlink.com

\begin{abstract}
Purpose We comparatively evaluated urethral stricture (US) treatment outcomes, efficacy and complications, using either holmium laser endourethrotomy (HLU) or optical internal urethrotomy (OIU) since studies such as this are scarce in literature.

Methods During 2003-2008, 50 men aged 1778 years were operated on for primary or refractory US, 32 (64\%) and 18 (36\%) patients, respectively. The average stricture length was $1.86 \mathrm{~cm}$. Strictures were single or multiple, forty-one (82\%) and nine (18\%) patients, respectively, and were located in the anterior or posterior urethra in $27(54 \%)$ and $32(64 \%)$ patients, respectively. US were iatrogenic in $32(64 \%)$ and idiopathic in 18 (36\%). Patients were divided into two groups, grpA and grpB, each containing 25 patients who were treated using either HLU or OIU, respectively. An evaluation scale of 1-3 was adopted and took maximum flow rate $\left(\mathrm{Q}_{\max }\right)$, postvoid residual (PVR), and quality of
\end{abstract}

S. A. Dutkiewicz - M. Wroblewski

Department of Urology, E. Michałowski Urological

Hospital, Katowice, Poland

S. A. Dutkiewicz $\cdot$ M. Wroblewski

Department of Prevention and Epidemiology

of Neoplasms, Institute of Public Health,

Faculty of Health Sciences, J. Kochanowski University,

Kielce, Poland

S. A. Dutkiewicz $(\square)$

2/56 Lachmana Street, Warsaw 02-786, Poland

e-mail: sad1947@wp.eu life (QL) into consideration. A score of '1 was very good, '2 was good, and '3 was poor.

Results Treatment results were evaluated after 3, 6, and 12 months, respectively. Evaluation of grpA was as follows: five (20\%), nine (36\%), and seven (28\%) patients scored a ' 1 ; thirteen $(52 \%)$, nine (20\%), and four $(16 \%)$ patients scored a ' 2 ; and seven (28\%), eleven (44\%), and fourteen (56\%) patients scored a ' 3 . Evaluation of grpB: seven (28\%), ten (40\%), and five (20\%) patients scored a '1; eleven (44\%), seven $(28 \%)$, and ten $(40 \%)$ patients scored a ' 2 ; and seven (28\%), eight (32\%), and ten ( $40 \%$ ) patients scored a ' 3 . Conclusions Neither complication rate nor degree of efficacy between HLU and OIU for US revealed a significant difference. We found both laser and conventional urethrotomies to be safe and effective modes of treatment.

Keywords Conventional urethrotomy $\cdot$ Endoscopic urethrotomy · Holmium laser endourethrotomy · Optical internal urethrotomy · Urethral stricture

\section{Introduction}

Since 1974, Sachse's optical internal urethrotomy (OIU) has been considered the treatment of choice for urethral stricture (US); however, the occurrence of refractory strictures has made results unsatisfactory 
with success rates of 33-60\% [1,2]. Since then, several alternatives have been evaluated and include the holmium laser, which was introduced into urological practice in the early ' $90 \mathrm{~s}$ and uses a pulsed monochrome light $(\lambda=2100 \mathrm{~nm})$ while allowing energy transfer through a 200-1000 $\mu \mathrm{m}$ fiber [3-5].

This study aimed to evaluate the outcomes of the laser and conventional urethrotomies that were performed at E. Michalowski Memorial Urology Hospital in Katowice, Poland.

\section{Patients and methods}

This prospective study included 50 men aged $17-78$ years $($ mean $=63.45$ ) with primary or refractory US who were operated on during 2003-2008 at E. Michalowski Memorial Urology Hospital in Katowice, Poland. The diagnosis of US was based on international prostate symptom scores (IPSS), quality of life (QL), clinical history, uroflowmetry (UF), ultrasonography (USG), and urethrography.

The etiology of US was primary in $32(64 \%)$ and refractory in $18(36 \%)$ patients. Stricture length did not exceed $3 \mathrm{~cm}$, and single stricture occurred in 41 $(82 \%)$ patients while multiple strictures occurred in nine $(18 \%)$. US of the anterior urethra were present in $27(54 \%)$ and posterior urethra in $32(64 \%)$ patients. All patients with refractory US were previously treated with OIU. The etiology of US was iatrogenic in $32(64 \%)$ and idiopathic in $18(36 \%)$. Iatrogenic causes were attributed to transurethral resection of prostate (TURP), transurethral resection of bladder tumor (TURBt), lower urinary tract stent, radiotherapy, and radical prostatectomy in seventeen (34\%), one $(2 \%)$, one $(2 \%)$, five $(10 \%)$, one $(2 \%)$, and seven (14\%) patients, respectively.

The predominant symptom was a weak urine stream, which occurred in 45 (90\%) patients. Other symptoms included refractory lower urinary tract infection, urine stream deviation, interrupted urine stream, painful micturition, urinary retention, difficulty initiating urination, and paradoxical urinary incontinence in seven (14\%), eight $(16 \%)$, seven (14\%), ten $(20 \%)$, nine $(18 \%)$, thirteen $(26 \%)$, and one $(2 \%)$ patient, respectively.

After clinical evaluation, patients were numbered and assigned to grpA or grpB (odd or even numbered patients, respectively) and were treated with HLU and
OIU, respectively. Laboratory tests, USG, postvoid residual (PVR), and UF $\left(\mathrm{Q}_{\max }\right.$ and $\left.\mathrm{Q}_{\text {ave }}\right)$ were determined pre- and postoperatively, together with IPSS and QL. Patients were evaluated at 3, 6, and 12 months postoperatively. An evaluation scale of 1-3 was adopted: a score of ' 1 was very good: $\mathrm{Q}_{\max }$ $>15 \mathrm{ml} / \mathrm{s}$, PVR < 50-ml, QL 0-1 points; '2 was good: $\mathrm{Q}_{\max }$ 8-14 ml/s, PVR 50-100 ml, QL 2-3 points; and '3 was poor: $\mathrm{Q}_{\max }<8 \mathrm{ml} / \mathrm{s}, \mathrm{PVR}>100 \mathrm{ml}$, QL 4-5 points.

\section{Surgical technique of urethrotomy}

The lithotomy position was used for all operations with subarachnoid anesthesia and perioperative ciprofloxacin prophylaxis $(2 \times 500 \mathrm{mg})$.

For HLU, The holmium laser (Coherent Inc.) used boasted $100 \mathrm{~W}$ of power and a 365-nm laser fiber. To begin, an optical urethrotome or a $21 \mathrm{~F}$ Storz cystoscope was inserted into the urethra along with a guide wire, both of which were followed by a urethrotome that was guided to the area of stricture. The 365-nm fiber of the laser was then inserted, and the cutting of the scar was initiated most commonly at the 12-o' clock position. The laser energy used was $0.8-1.5 \mathrm{~J}$ (mean, $1.2 \mathrm{~J}$ ) with a frequency of $8-15 \mathrm{~Hz}$ (mean, $12 \mathrm{~Hz}$ ) and power of 6.4-22.5 W (mean, $14 \mathrm{~W}$ ).

During OIU, a 21 Charr optical urethrotome was inserted into the urethra, and the US repair was initiated in the conventional way. Lastly, urethroscopy was performed, an $18 \mathrm{~F}$ Foley catheter was placed, and patients were released.

\section{Statistics}

Values for the following descriptive parameters were calculated: average values, standard deviations, calculated minimum and maximum values for measurable variables, and the percentages for non-measurable variables (qualitative). The Shapiro-Wilk, Mann-Whitney $U$, and Friedman's tests were used and analysis of results was divided into two stages. The first entailed the calculation of fractions (percentages) with respect to quality characteristics: types and location of US, etiology, symptoms, as well as the results of IPSS and QL. During the second stage, the following values for basic descriptive parameters of measurable variables were analyzed: age of patient, length of US, $\mathrm{Q}_{\max }$, and PVR. 


\section{Results}

We began by assessing the differences in type, size, and location of US between the studied groups and found no statistically significant differences (Fig. 1). Then, we analyzed the prevalence of the typical symptoms associated with US in both of the studied groups and also found no statistically significant differences between the groups.

Before treatment, IPSS was assessed and the average score for both groups was 21.2 points. After treatment, however, grpA obtained 21.6 points while grpB obtained 20.8 , but no statistically significant difference was found between the groups $(P>0.05)$. IPSS was also assessed during the 12-month follow-up and showed improvement, but revealed no statistically significant difference between the groups $(P>0.05)$ with average scores of 17.2 and 17.4 points for grpA and grpB, respectively.

We also assessed QL before and after treatment as well as during 12-month follow-up. Before treatment, grpA and grpB scored an average 4.6 points. After treatment, patients scored 4.7 and 4.5 points, respectively, with no statistically significant difference between the groups $(P>0.05)$. During 12-month follow-up, they scored 2.6 and 2.8 points, respectively, with no statistically significant difference between the groups $(P>0.05)$.

Values for basic descriptive parameters (age, length of stricture, UF, and PVR) were calculated for both groups, grpA and grpB, and can be found in Tables 1 and 2, respectively. Evaluation of the data revealed that the majority of characteristics (especially PVR) deviated from the normal distribution. Analysis of patient age and length of US revealed no statistically significant differences between the groups $(P>0.05)$. Figure 2 presents the results of UF $\left(Q_{\max }\right)$, which did not reveal any statistically significant differences between the studied groups irrespective of the observation stage $(P>0.05)$. Values of PVR before surgery were significantly higher in grpA than in grpB; however, the remaining observation stages did not show any statistically significant differences $(P>0.05)$ (Fig. 3).

Evaluation for the significance of changes in the measurable characteristics in each of the studied groups revealed a deviation from the normal distribution, and therefore, further statistical analysis was performed using Friedman's test. Figures 4, 5 present the results for grpA and Figs. 6, 7 for grpB.

Very high $\mathrm{Q}_{\max }$ value changes were observed in grpA (Fig. 4): after 3 months a strong increase $(P=0.0002)$ and after 6 months an insignificant decrease $(P>0.05)$ were observed in relation to baseline, but still significantly higher than before surgery $(P=0.002)$. After 12 months, a further insignificant decrease occurred $(P>0.05)$ reaching a level higher than baseline, but without statistical significance $(P>0.05)$.

Resemble was the results for statistical evaluation of changes in $\mathrm{Q}_{\text {ave }}$. The decline seen from the third to twelfth months after surgery was statistically significant. $\mathrm{Q}_{\mathrm{ave}}$ almost returned to preoperative baseline.

Figure 5 shows the significance of changes in PVR in grpA. The very high baseline PVR experienced a sharp decline 3 months after surgery
Fig. 1 Types and localizations of urethral strictures in studied groups $\mathrm{A}$ and $\mathrm{B}$-results of tests from both groups

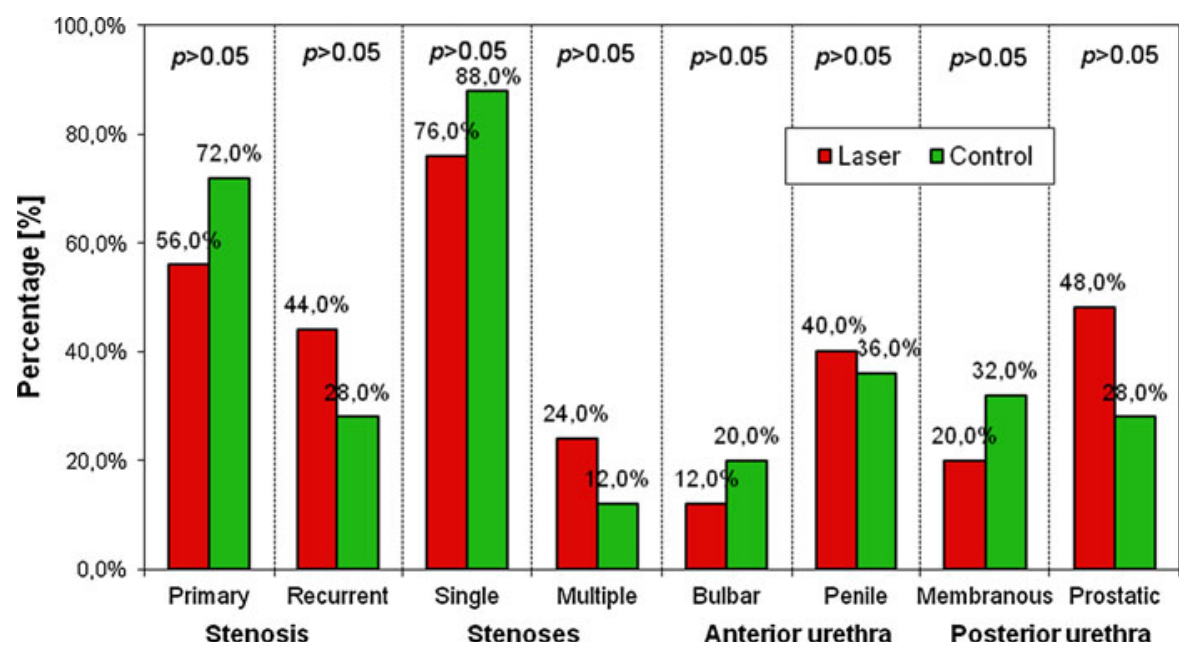


Table 1 Descriptive parameters and verification of 'normal' distribution of analyzed measureable characteristics in the studied patients of group A (laser)

\begin{tabular}{|c|c|c|c|c|c|c|c|}
\hline Group & Characteristics & $\begin{array}{l}\text { Observation stage } \\
\text { (months) }\end{array}$ & Mean & SD & Min & Max & Shapiro-Wilk test \\
\hline \multirow[t]{14}{*}{ Laser (group A) } & Age (years) & Before operation & 61.2 & 16.1 & 17.0 & 79.0 & $<0.05$ \\
\hline & Length of stricture $(\mathrm{cm})$ & Before operation & 1.86 & 1.26 & 0.50 & 3.00 & $<0.05$ \\
\hline & \multirow[t]{4}{*}{$\mathrm{Q}_{\max }$-maximum flow $(\mathrm{ml} / \mathrm{s})$} & Before operation & 4.96 & 3.13 & 0.00 & 13.00 & $>0.05$ \\
\hline & & 3 & 11.44 & 8.14 & 0.00 & 37.00 & $<0.05$ \\
\hline & & 6 & 10.72 & 8.43 & 0.00 & 34.00 & $>0.05$ \\
\hline & & 12 & 10.60 & 10.04 & 0.00 & 36.00 & $<0.05$ \\
\hline & \multirow[t]{4}{*}{$\mathrm{Q}_{\text {ave }}$-average flow $(\mathrm{ml} / \mathrm{s})$} & Before operation & 2.96 & 1.72 & 0.00 & 6.00 & $>0.05$ \\
\hline & & 3 & 6.68 & 4.04 & 0.00 & 14.00 & $>0.05$ \\
\hline & & 6 & 6.52 & 4.99 & 0.00 & 20.00 & $>0.05$ \\
\hline & & 12 & 5.28 & 4.61 & 0.00 & 17.00 & $<0.05$ \\
\hline & \multirow[t]{4}{*}{ PVR retention (ml) } & Before operation & 87.6 & 38.8 & 0.00 & 154.0 & $>0.05$ \\
\hline & & 3 & 35.05 & 33.89 & 0.00 & 150.00 & $<0.05$ \\
\hline & & 6 & 40.64 & 41.60 & 0.00 & 200.00 & $<0.05$ \\
\hline & & 12 & 37.48 & 40.99 & 0.00 & 170.00 & $<0.05$ \\
\hline
\end{tabular}

Table 2 Descriptive parameters and verification of 'normal' distribution of analyzed measureable characteristics in the studied patients of group B (classical urethrotomy)

\begin{tabular}{|c|c|c|c|c|c|c|}
\hline \multicolumn{7}{|l|}{ Classical urethrotomy (group B) } \\
\hline Age (years) & Before operation & 65.7 & 11.9 & 37.0 & 87.0 & $>0.05$ \\
\hline Length of stricture $(\mathrm{cm})$ & Before operation & 1.66 & 1.02 & 0.50 & 3.00 & $<0.05$ \\
\hline \multirow[t]{4}{*}{$\mathrm{Q}_{\max }$-maximum flow $(\mathrm{ml} / \mathrm{s})$} & Before operation & 5.80 & 4.09 & 0.00 & 14.00 & $>0.05$ \\
\hline & 3 & 11.92 & 6.84 & 0.00 & 29.00 & $>0.05$ \\
\hline & 6 & 11.80 & 9.35 & 0.00 & 39.00 & $>0.05$ \\
\hline & 12 & 9.80 & 7.85 & 0.00 & 34.00 & $<0.05$ \\
\hline \multirow[t]{4}{*}{$\mathrm{Q}_{\text {ave }}$-average flow $(\mathrm{ml} / \mathrm{s})$} & Before operation & 3.24 & 2.03 & 0.00 & 7.00 & $>0.05$ \\
\hline & 3 & 6.52 & 3.56 & 0.00 & 14.00 & $>0.05$ \\
\hline & 6 & 6.80 & 4.84 & 0.00 & 20.00 & $>0.05$ \\
\hline & 12 & 5.44 & 3.76 & 0.00 & 15.00 & $<0.05$ \\
\hline \multirow[t]{4}{*}{ PVR Retention (ml) } & Before operation & 70.6 & 43.2 & 0.00 & 198.0 & $<0.05$ \\
\hline & 3 & 47.54 & 52.55 & 0.00 & 268.00 & $<0.05$ \\
\hline & 6 & 52.32 & 56.17 & 0.00 & 268.00 & $<0.05$ \\
\hline & 12 & 48.40 & 34.93 & 0.00 & 115.00 & $>0.05$ \\
\hline
\end{tabular}

$(P<0.0001)$ and further decreased over the next 3 months (insignificant, $P>0.05$ ), reaching a level markedly lower than baseline $(P<0.0001)$. However, in the last period, a statistically insignificant increase appeared $(P>0.05)$. Ultimately, the PVR approached baseline, although still lower, showing statistical significance $(P=0.0014)$.

$\mathrm{Q}_{\max }$ for grpB revealed similar changes as in grpA, both as to character and significance (Fig. 6). The nature of changes in $\mathrm{Q}_{\mathrm{ave}}$ in grpB is similar to that in grpA.

Shown in Fig. 7 are changes in the nature of PVR in grpB that are similar to those found in grpA. After 3 months, there was a decline in PVR, which grew slowly at first then slightly faster later. The final PVR of grpB was closer to the baseline than that observed in grpA. PVR after 1 year of observation was slightly lower (no significance) compared to baseline. 


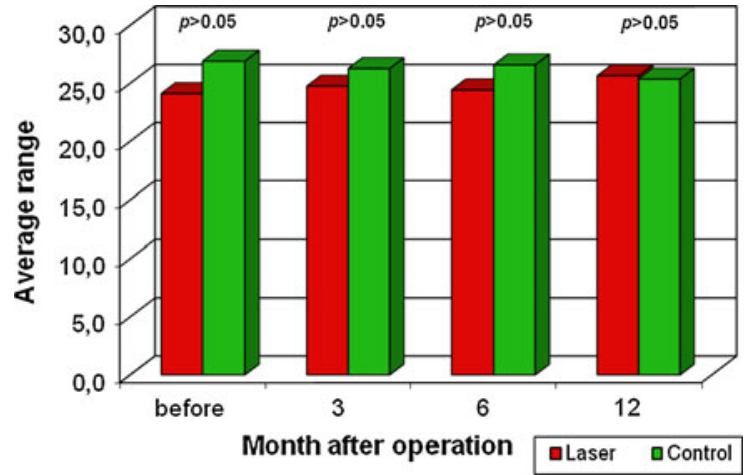

Fig. 2 Values of maximum urine flow $\mathrm{Q}_{\max }$ in both groups during consecutive observation stages-results of the MannWhitney test

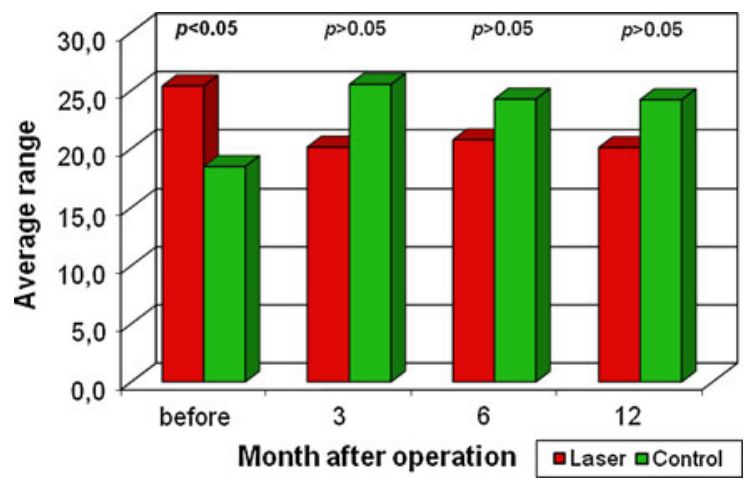

Fig. 3 Urine retention (R) in both groups during consecutive observation stages-results of the Mann-Whitney test

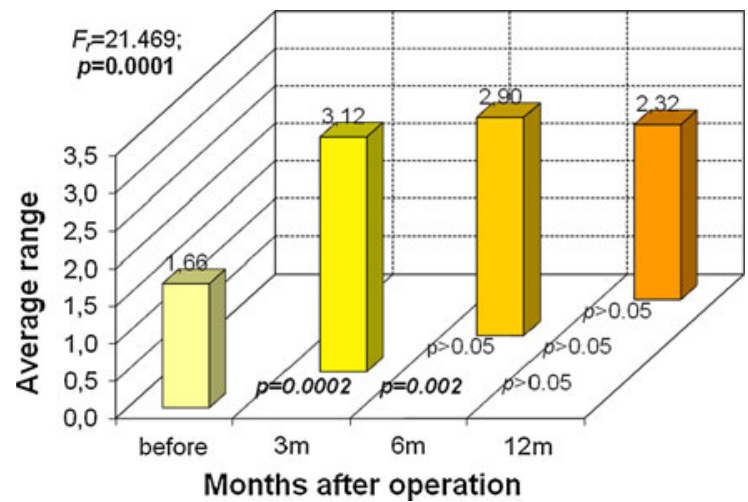

Fig. 4 Evaluation of significance of changes in maximum urine flow rate $\left(Q_{\max }\right)$ during consecutive observation stages in group A-results of Friedman test

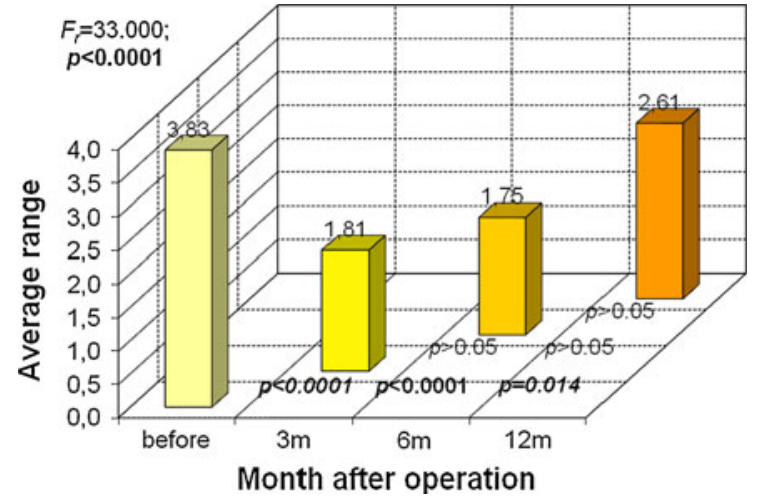

Fig. 5 Evaluation of significance of changes in urine retention (PVR) during consecutive observation stages in group Aresults of Friedman test

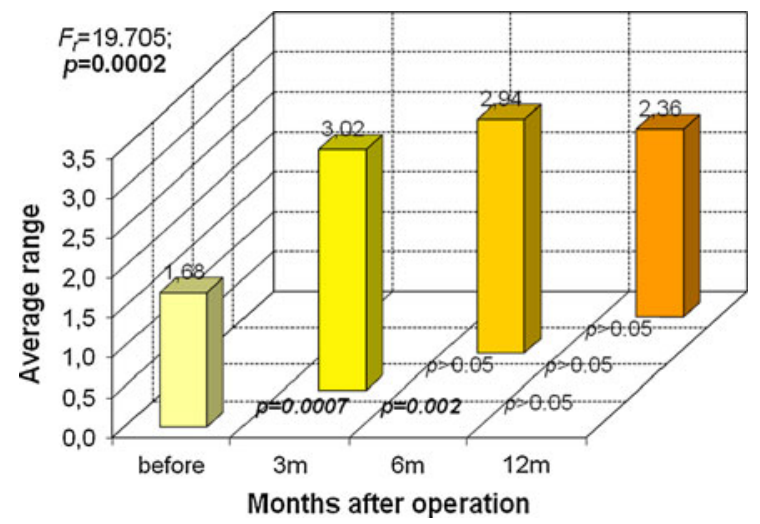

Fig. 6 Evaluation of significance of changes in maximum urine flow rate $\left(\mathrm{Q}_{\max }\right)$ during consecutive observation stages in group B-results of Friedman test

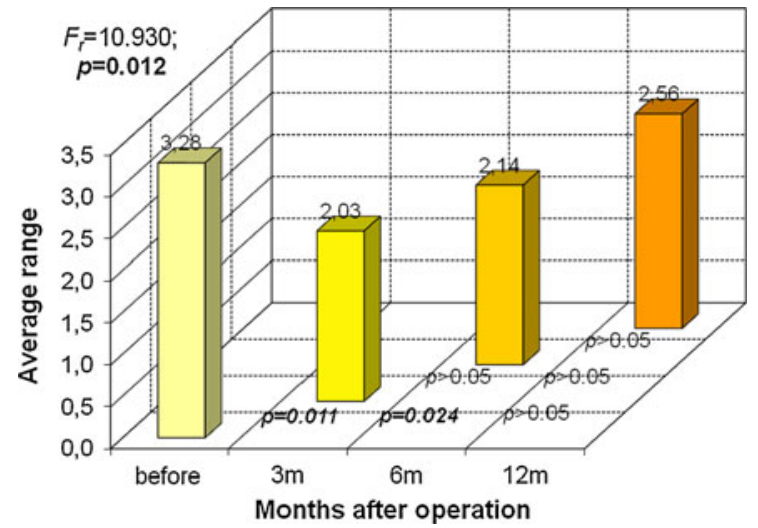

Fig. 7 Evaluation of significance of changes in urine retention (R) during consecutive observation stages in group B-results of Friedman test 
Table 3 Results of treatment for urethral stricture of group A (laser) and group B (classical urethrotomy) according to adopted criteria

\begin{tabular}{|c|c|c|c|c|c|c|}
\hline \multirow{2}{*}{$\begin{array}{l}\text { Treatment result } \\
\text { Group }\end{array}$} & \multicolumn{2}{|l|}{3 months } & \multicolumn{2}{|l|}{6 months } & \multicolumn{2}{|l|}{12 months } \\
\hline & A & $\mathrm{B}$ & A & B & A & B \\
\hline Very good and good & $18(72 \%)$ & $18(72 \%)$ & $14(56 \%)$ & $17(68 \%)$ & $11(44 \%)$ & $15(60 \%)$ \\
\hline Poor & $7(28 \%)$ & $7(28 \%)$ & $11(44 \%)$ & $8(32 \%)$ & $14(56 \%)$ & $10(40 \%)$ \\
\hline
\end{tabular}

Neither group experienced significant intra- or postoperative complications, nor clinically significant bleeding requiring blood transfusion.

As seen in Table 3, according to the adopted criteria for evaluation of treatment results, it was found that in grpA: a '1 was obtained by five (20\%) patients during 3-month follow-up, nine $(36 \%)$ on 6-month, and seven (28\%) by 12-month; a '2 was obtained by thirteen $(52 \%)$, five $(20 \%)$, and four $(16 \%)$; and a ' 3 was obtained by seven ( $28 \%)$, eleven (44\%), and fourteen (56\%), respectively. In grpB: a '1 was obtained by seven (28\%), ten (40\%), and five (20\%); a ' 2 by eleven (44\%), seven (28\%), and ten (40\%); and a ' 3 by seven ( $28 \%$ ), eight (32\%), and ten $(40 \%)$ patients, respectively.

\section{Discussion}

US in men are congenital or acquired pathologies leading to narrowing of the urethral lumen, causing subvesical obstruction. Untreated, they lead to irreversible changes in the upper and lower urinary tract. Being characterized by a high recurrence, US require patients to undergo numerous operations that expose them to additional complications. The last "gold standard" endoscopic urethrotomy was Sachse's, but restricture occurs in $89 \%$ of patients with efficacy of 35-60\% according to EAU Guidelines (2008) [1, 2]. Poor results were observed in $56 \%$ of our grpA after 1 year. Most of the restrictures appeared within the first 12 months, even in patients after second urethrotomy [6].

Since 1984, lasers have been used in urethrotomies: Nd:YAG [7-14], argon [15, 16], diode [17], Ho:YAG [18], and KTP [19]. The major advantages of laser treatments include reduced blood loss and hospital stay [20]. The Ho:YAG, or holmium, laser demonstrates the shallowest absorption $(<0.5 \mathrm{~mm})$ with smallest effect on surrounding tissues and is presumed to reduce scar tissue formation. Regardless, data published until now have not demonstrated a significantly better outcome with Ho:YAG treatment over other types of laser or cold-knife urethrotomy. Perhaps, the postoperative development of restricture not only depends on laser type, but also on many other factors [21].

The results of treatment from grpA (Ho:YAG laser $100 \mathrm{~W}$ ) were compared with the results of other authors [6, 22-26]. The etiology of Kamp's US patients [6] was similar to our patients. Kamp performed all urethrotomy incisions at 6- or 12-o'clock, or both, in the area of maximum cicatricial tissue narrowing. There was no difference in the complication rate when an additional 6-o'clock incision was made [6]. A similar procedure and laser parameters were adopted for the treatment of our patients.

In the postoperative period, Kamp [6] maintained an $18 \mathrm{~F}$ catheter for 4 days and administered intraurethral triamcinolone to all patients after catheter removal. Conversely, we maintained the catheter for 10 days without intraurethral steroid administration. The duration of catheterization after endoscopic incision of US remains under discussion with various periods from 24 h to 6 weeks [21, 27, 28].

In 22(68.7\%) of Kamp's patients, second intervention was unnecessary. Ten of his patients experienced restricture; four $(12.5 \%)$ of which were retreated with Ho:YAG laser; and six (18.7\%) underwent urethroplasty using buccal mucosa. Two patients underwent second urethrotomy; however, 24 (75\%) initial treatments were considered successful after 13-38 months. Just as in Kamp's patients [6], no intraoperative or postoperative complications occurred.

The Ho:YAG laser offers a significant advantage with its coagulation ability. Rated as a safe and minimally invasive therapeutic option comparable with conventional urethrotomy, it can be at least an alternative to urethroplasty when concurrent diseases do not qualify patients for open urethral reconstruction [6].

Hossain et al. [22] evaluated the results of treating US up to $2 \mathrm{~cm}$ by using a Ho:YAG laser of similar energy in men aged 15-60 years after 12 months. The 
catheter was left for $24 \mathrm{~h}$ postoperatively. Every 3 months, the following tests were conducted: UF, urethrography, and voiding cystography. They found that in $27(90 \%)$ patients, $Q_{\text {ave }}$ exceeded $16 \mathrm{ml} / \mathrm{s}$ and the urethral caliber was appropriate. However, three $(10 \%)$ patients presented a narrower stream of urine $\left(\mathrm{Q}_{\text {ave }}<8.0 \mathrm{ml} / \mathrm{s}\right)$ and urethrography confirmed refractory US. In the assessment of our own patients, the basic parameter of success was $\mathrm{Q}_{\max }$, not $\mathrm{Q}_{\mathrm{ave}}$, and urethrography was not performed.

The literature regarding urethrotomy up till now has not presented uniform criteria for evaluating the effectiveness of US treatment. Kamp's criteria [6] was lack of necessity for second intervention while Hossain et al. [22] considered it to be failure to achieve appropriate urine flow $\left(\mathrm{Q}_{\mathrm{ave}}<8 \mathrm{ml} / \mathrm{s}\right)$ as well as urethral restricture in urethrography, but most of these refractory strictures appeared within the first 12 months [6].

In our goal to objectively analyze the results of urethrotomy using the Ho:YAG laser, we randomly created a similar group of patients who were treated with classical urethrotomy (each group contained 25 , without statistically significant differences in etiology of stricture, their number, localization, length, or relevant symptoms). Assessment of treatment effectiveness and complications were made on the basis of UF in the third, sixth, and twelfth months after treatment. The results obtained and their evaluation on the basis of adopted criteria did not confirm a higher treatment effectiveness of the holmium laser endourethrotomy (HLU) over the classical optical internal urethrotomy (OIU) at 1-year follow-up.

\section{Conclusion}

Neither complication rate nor degree of efficacy between HLU and OIU for US revealed a significant difference. We found both laser and conventional urethrotomies to be safe and effective modes of treatment.

Open Access This article is distributed under the terms of the Creative Commons Attribution Noncommercial License which permits any noncommercial use, distribution, and reproduction in any medium, provided the original author(s) and source are credited.

\section{References}

1. Sachse H (1974) Zur behandlung der Harnrohrenstriktur; Die transurethrale Schlitzung unter Sicht mit scharfen Schnitt. Fortschr Med 92:12-15

2. Giannakopoulos X, Grammeniatis E, Gratzios A et al (1997) Sachse urethrotomy versus endoscopic urethrotomy plus transurethral resection of the fibrous callus (Guillemin's technique) in the treatment of urethral stricture. Urology 49:243-247

3. Floratos DL, De la Rosette JJMCH (1999) Laser in urology. BJU Int 1(4):15-24

4. Van Hillegersberg R (1997) Fundaments of laser surgery. Eur J Surg 163:3-11

5. Wollin TA, Denstedt JD (1998) The holmium laser in urology. J Clin Laser Med Surg 16:13-20

6. Kamp s, Knoll T, Osman MM et al (2006) Low-power Holmium: YAG laser urethrotomy for treatment of urethral strictures: functional outcome and quality of life. J Endourol 20(1):38-41

7. Costello AJ, Johnson DE, Bolton DM (1992) Nd: YAG laser ablation of the prostate as a treatment for benign prostatic hypertrophy. Lasers Surg Med 12:121-124

8. Dogra PN, Aron M, Rajeev TP (1999) Core through urethrotomy with the neodymium: YAG laser for posttraumatic obliterative strictures of the bulbomembranous urethra. J Urol 161(1):81-84

9. Dogra PN, Nabi G (2002) Core-through urethrotomy using the neodymium: YAG laser for obliterative urethral strictures after traumatic urethral disruption and/or distraction defects: long-term outcome. J Urol 167(2 Pt 1):543-546

10. Dogra PN, Nabi G (2003) Nd-YAG laser core-through urethrotomy in obliterative posttraumatic urethral strictures in children. Pediatr Surg Int 19(9-10):652-655

11. Dogra PN, Nabi G (2002) Neodymium-YAG laser core through urethrotomy in obliterative posttraumatic urethral strictures after failed initial urethroplasty. Urol Int 68(4): 265-267

12. Gurdal M, Tekin A, Yucebas E, Kirecci S, Sengor F (2003) Contact neodymium: YAG laser ablation of refractory urethral strictures using a side-firing fiber. J Endourol 17(9): 791-794

13. Nabi G, Dogra PN (2002) Endoscopic management of posttraumatic prostatic and supraprostatic strictures using Neodymium-YAG laser. Int J Urol 9(12):710-714

14. Perkash I (1997) Ablation of urethral strictures using contact chisel crystal firing neodymium: YAG laser. J Urol 157(3):809-813

15. Adkins WC (1988) Argon laser treatment of urethral stricture and vesical neck contracture. Lasers Surg Med 8(6): 600-603

16. Becker HC, Miller J, Noske HD, Klask JP, Weidner W (1995) Transurethral laser urethrotomy with argon laser: experience with 900 urethrotomies in 450 patients from 1978 to 1993 . Urol Int 55(3):150-153

17. Guazzieri S, Bertoldin R, D’Inca G, De Marchi G, Mazzariol C, Galetti-Prayer T, Cecchetti W (2001) 980-nm diode laser treatment for refractory urethral strictures. Eur Urol 39(Suppl 2):19-22 
18. Monga M, Gordon Z, Alexandrescu B (2001) Obliterated urethra: holmium: yttrium-aluminum-garnet cut-to-light with urolume stenting. Tech Urol 7(4):266-270

19. Turek PJ, Malloy TR, Cendron M, Carpiniello VL, Wein AJ (1992) KTP-532 laser ablation of urethral strictures. Urology 40(4):330-334

20. Montorosi F, Naspo R, Salonia A et al (2004) Holmium laser enucleation versus transurethral resection of the prostate: results from a 2-center, prospective, randomized trial in patients with obstructive benign prostatic hyperplasia. J Urol 172:1926-1929

21. Matsouka K, Inoue M, Iida S et al (2002) Endoscopic antegrade laser incision in the treatment of urethral stricture. Urology 60:968-972

22. Hossain AZ MZ, Khan SA, Hossain S, Salam MA (2004) Holmium laser urethrotomy for urethral stricture. Bangladesh Med Res Counc Bull 30(2):78-80

23. Dogra PN, Ansari MS, Gupta NP, Tandon S (2004) Holmium laser core- through urethrotomy for traumatic obliterative strictures of urethra: initial experience. Urology 64(2):232-235 discussion 235-6
24. Gupta NP, Ansari MS (2004) Holmium laser core through internal urethrotomy with explanation of urolume stent. An ideal approach for a complicated posterior urethral stricture. Int J Urol 11(5):343-344

25. Hayashi T, Yoshinaga A, Ohno R, Ishii N, Watanabe T, Yamada T, Kihara K (2005) Successful treatment of refractory vesicourethral stricture after radical prostatectomy with holmium laser: report of three cases. Int J Urol 12(4):414-416

26. Futao S, Wentong Z, Yan Z, Qingyu D, Aiwu L (2006) Application of endoscopic Ho:YAG laser incision technique treating urethral strictures and urethral atresias in pediatric patients. Pediatr Surg Int 22(6):514-518

27. Peterson AC, Webster GD (2004) Management of urethral stricture disease: developing options for surgical intervention. BJU Int 94(7):971-976

28. Borówka A w Borkowski A, Borówka A (1990) Urazy narządów miednicy mniejszej i zewnętrznych narządów płciowych. PZWL, Warszawa, pp 154-6 